\title{
Preface: A Tribute to Angus Morton Bowie
}

\author{
The mediocre teacher tells. \\ The good teacher explains. \\ The superior teacher demonstrates. \\ The great teacher inspires. \\ - William Arthur Ward
}

Those who are lucky enough to have been taught by Angus Bowie, like the editors of this volume, would readily agree that he is a prime example of a 'great teacher'. And yet he exceeds this designation, since he is also a world-leading scholar, a supportive colleague and a committed friend.

Born in 1949, Bowie attended St Peter's School, York, and subsequently read Classics at Emmanuel College, Cambridge. In the footsteps of his doctoral supervisor, Pat Easterling, Bowie developed his unique philological idiom, so appealing to young classicists and senior scholars alike. In all his work pithy expression, structural rigour and detailed textual criticism go hand in hand with interpretative insights of extraordinary literary sensitivity.

Bowie's thesis, The Poetic Dialect of Sappho and Alcaeus (1979, published in 1981), already showed that he could produce 'very important work [...] characterised by the flexibility of the method observed in dealing with diverse questions'. In 1977 he took up a position as Lecturer in Greek at the University of Liverpool, and in 1981 he moved to The Queen's College, Oxford, where he stayed until his retirement in 2016, as Lobel Praelector in Classical Languages and Literature.

In 1993 Bowie published a ground-breaking monograph, which established him as a leading scholar of Greek comedy: Aristophanes: Myth, Ritual and Com$e d y$. Reading the extant plays of Aristophanes in the light of structural anthropology, Bowie showed once and for all that they have nothing of the loose and incidental structure of a revue. A review of the time predicted that 'future studies of myth and ritual in Aristophanes and other poets of Old Comedy, will surely be indebted to Bowie's important first steps'; ${ }^{2}$ yet the impact of the book (reprinted in 1994, 1995, 1996, 2005, and translated into Modern Greek in 1999) proved to be much wider. To the present day it remains a challenge to find an academic library, with a minimum coverage of Greek comedy, which does not host that work - a reward that very few books in the field have achieved after Kenneth Dover's Aristophanic Comedy (1972).

1 Liberman 1987, 167; the translation is our own.

2 Rosen 1994.

https://doi.org/10.1515/9783110646269-202 
In more recent years Bowie has turned to producing commentaries. Three of them have appeared in the Cambridge 'Green and Yellow' series: Herodotus: Histories VIII (2007), Homer: Odyssey XIII-XIV (2013) and, most recently, Homer: Iliad III (2019). Each of these commentaries stands out for 'the care which Bowie has taken in order to maximize its usefulness for students'3 and for being 'particularly strong and up to date in its synthesis of historical and literary observations. In this sense his work outshines earlier, unsatisfactory English commentaries' . 'The bibliography is abundant and modern. The notes that accompany the commentary are exemplary. Bowie gives just the right amount of information, whether it is on the history of the word, or its usage, or background of a custom. Every so often he intersperses a prose summary of the text coming up, marvels of compression and lucidity. ${ }^{5}$ Following the same principles, but on a larger scale, Bowie is currently preparing a commentary on Iliad XXI-XXIV for Lorenzo Valla/Mondadori.

In addition to being an excellent scholar - for a full list of his publications see the bibliography on pp. 311-12 - Bowie has supported the Oxford academic community through various administrative roles: Senior Tutor (1996-2004) and Fellow Librarian (2010-2014) at The Queen's College, Chairman of the Sub-Faculty of Classical Languages and Literature (2004-2007), Chairman of the Faculty of Classics (2011-2014), Assessor of the University of Oxford (1998-1999) and Chairman of the Boards of Study of the Department of Continuing Education for many years. He was Editor of the Journal of Hellenic Studies (2006-2011), and after that he took an active part in founding the Centre for Manuscript and Text Cultures (CMTC) at The Queen's College and its accompanying online journal, Manuscript and Text Cultures.

Above all, Bowie was passionately devoted to teaching and mentoring his students. In retirement he still runs some of the most popular seminars at Oxford, continues to teach Greek to aspiring teenage classicists at the annual JACT summer school at Bryanston and delivers lectures to academic and non-academic audiences across the UK and abroad. This non-retirement retirement, as Euripides would put it, and his persistent support for the younger generations show that he never ceased looking upon his discipline with youthful enthusiasm: adventurous and open-minded, affable and humble (he still calls his engagement with Ancient Near Eastern cultures ‘exercises').

3 Bostock 2015.

4 Bakker 2010.

5 Powell 2015. 
For this ethos and his contributions to research and teaching we dedicate the present volume to our didaskalos and cordially wish him the best for the future. This Festschrift covers only one of the honorand's research interests - we would have had to write an entire History of Greek Literature otherwise - but in that way it reveals the deep impact of his work. Stemming from a conference on Greek Comedy held at Oxford in May 2017 and including further invited submissions, the volume brings together former students and colleagues of Angus Bowie, personal friends and intellectual interlocutors, senior scholars and graduate students. Their contributions offer a variety of fresh approaches to the texts he studied and taught over so many years.

Angus is one of those giants on whose shoulders we are grateful to stand.

The Editors

Oxford, December 2019 


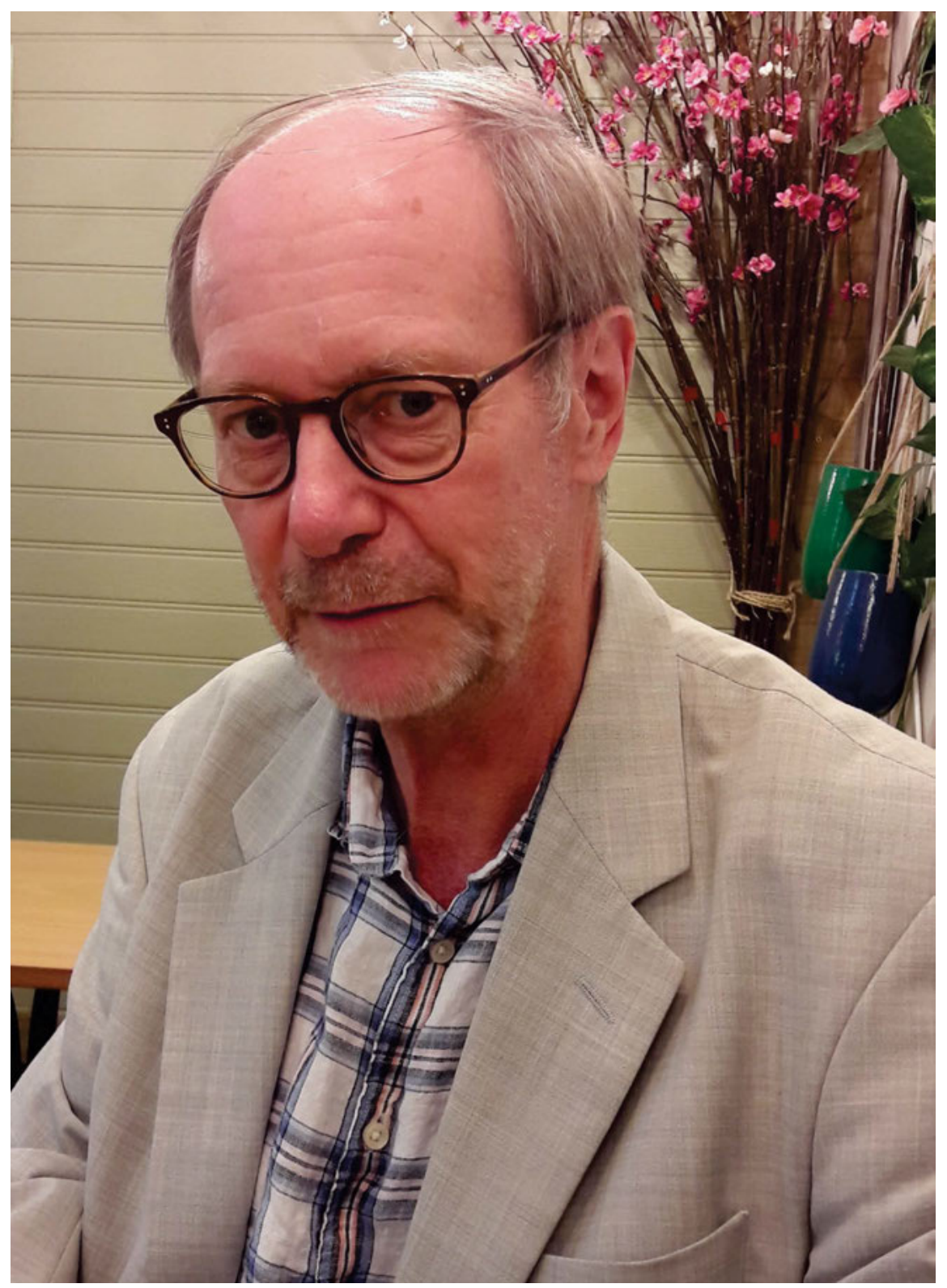

Angus M. Bowie 